\title{
Fernando Bonassi e a reinvenção do microconto na literatura brasileira contemporânea
}

\author{
Marcelo Spalding *
}

\begin{abstract}
Resumo: No mesmo ano em que um conjunto de micronarrativas de Fernando Bonassi encerra a antologia Os cem melhores contos brasileiros do século, o autor publica o livro Passaporte, apenas com micronarrativas, reafirmando a consolidação do microconto na literatura contemporânea brasileira. Bonassi também participa, anos depois, da coletânea Os cem menores contos do século, onde o reducionismo é levado ao extremo numa antologia que se denomina de microcontos. A origem dessa nova estética remonta às teorias do conto, ao minimalismo $\mathrm{e}$ à literatura norte-americana da geração de Raymond Carver - e seus efeitos já se fazem sentir na prosa contemporânea.
\end{abstract}

Palavras-chave: Microconto; Micronarrativa; Fernando Bonassi; Conto; Literatura Contemporânea

\begin{abstract}
In the same year that a group of Fernando Bonassi's micro fictions closes the anthology $O \mathrm{~s} \mathrm{cem}$ melhores contos do século, the author releases Passaporte, a micro fiction only book, which contributed to consolidate the micro fiction in Brazilian contemporary literature. Years later, the author also takes part in the anthology Os cem menores contos brasileiros do século, in which authors were invited to write stories with less than 50 letters. The origin of this literature goes back to the short story theories, to the minimalism and to the North American literature during the period of Raymond Carver's generation. Its effects can already be observed in contemporary narratives.
\end{abstract}

Keywords: Microfiction; Flash Fiction; Fernando Bonassi; Short Story; Brazilian Literature

É preciso começar por uma ponderação: toda seleção é subjetiva; e assim o é toda antologia; por mais representativa que ela se pretenda em determinado gênero, momento histórico ou espaço geográfico. Mas isso não significa que elas não tenham validade, muito pelo contrário, por vezes são essas antologias que trazem o passado de volta, compilam textos espalhados e esquecidos - e elucidam momentos literários importantes. Este parece ser o caso de Os Cem Melhores Contos Brasileiros do Século (2001), tanto pela credibilidade do organizador, o professor Ítalo Moriconi, e da Editora, Objetiva, como pela presença de autores e textos consagrados que vão de Machado a Scliar, passando por Lima Barreto, Clarice Lispector, os Rubens Braga e Fonseca, os Andrades Mario e Carlos Drummond, Dalton Trevisan, Sérgio Sant'anna e outros tantos. A compilação inclui contos canônicos como "Pai Contra Mãe" e "Feliz Ano Novo", mas Moriconi já na apresentação alerta:

\footnotetext{
* Marcelo Spalding é graduado em Jornalismo pela Universidade Federal do Rio Grande do Sul e mestrando em Literatura Brasileira na mesma Instituição.
} 
Na seleção aqui apresentada foram feitas algumas escolhas pouco ortodoxas, que se justificam, além da qualidade intrínseca do texto, por indicar ao leitor a possibilidade do gênero conto, a capacidade que o conto tem de confluir e confundir-se com gêneros próximos (MORICONI, 2001, p. 15).

A partir dessa explicação o leitor não se surpreenderá ao ler, na década de 70, "Aí pelas três da tarde", uma narrativa de Raduan Nassar com apenas 356 palavras - e escrita com verbos imperativos como largue, avance, não exagere. Não se surpreenderá porque facilmente o leitor encontra uma personagem, "este ser fictício que inaugura a narrativa" (CÂNDIDO, 1976, p. 56), além de "um discurso integrando uma sucessão de acontecimentos de interesse humano na unidade de uma mesma ação" (BREMOND, 1973, p. 113-114). Mas, possivelmente, o leitor, mesmo acostumado com o gênero e suas nuanças, depararar-se-á surpreso com o conto "15 cenas de descobrimento de Brasis", de Fernando Bonassi, que encerra a antologia. Trata-se de quinze micronarrativas independentes, com títulos também independentes, sendo a unidade apenas sugerida pelo título do conto, ou seja, de que o cenário é o Brasil em processo de descobrimento. Algumas, como "Turismo ecológico", fazem referência ao descobrimento histórico - esta trata de um missionário e o conflito entre brancos e índios. Outras, como "Planalto Central", retratam um país do presente, mas ainda a ser descoberto.

O nome completo de Wilson é Wilson Patachó, mas isso tá na cara. Entre Paranã e Gurupi todo mundo o conhece como "Índio". Na verdade como "Índio do Posto Shell". Wilson, ou Índio do Posto Shell, também é conhecido por fazer negócio com os caminhoneiros. Tem duas filhas pra oferecer. Pega-se em Paranã e larga-se em Gurupi, ou vice-versa. Uma chama-se Cibele Patachó e a outra Pamela Patachó. Cibele tem todos os dentes, Pamela nenhum e, justamente por isso, é a preferida pra coisa que aqueles homens brancos mais gostam de fazer (BONASSI, 2001, p. 605).

O mesmo leitor de "Aí pelas três da tarde" encontrará em "Planalto Central" personagens (Wilson e suas filhas), sucessão, ação e até mesmo conflito; mas terá dificuldades em relacionar este parágrafo com qualquer outro que seria de um conto uno.

Minha terra tem campos de futebol onde cadáveres amanhecem emborcados pra atrapalhar os jogos. Tem uma pedrinha cor-de-bile que faz 'ruim' na cabeça da gente. Tem também muros de bloco (sem pintura, é claro, que tinta é a maior frescura quando falta mistura), onde pousam cacos de vidro pra espantar malaco. Minha terra tem HK, AR15, M21, 45 e 38 (na minha terra, 32 é uma piada). As sirenes que aqui apitam, apitam de repente e sem hora marcada. Elas não são mais as das fábricas, que fecharam. São mesmo é dos camburões, que vêm fazer aleijados, trazer tranquiilidade e aflição (BONASSI, 2001, p. 607).

Intitulado "Canção do Exílio", esse "parágrafo" é uma paródia contemporânea do poema de Gonçalves Dias. Aqui o cenário é urbano, enquanto no texto anterior o cenário era o Planalto Central; as personagens são outras e até mesmo o foco narrativo é diferente. Nem será preciso reproduzir os demais parágrafos para concluirmos que, ao invés de um único conto, estamos diante de quinze narrativas, ou micronarrativas, devido ao seu tamanho. E a 
escolha de um conjunto como este - para fechar uma antologia de contos tão representativa do século XX - é motivo suficiente para pensarmos na importância do que se convencionou chamar microcontos ou micronarrativas.

Segundo referência dos editores de Cem Melhores, "15 cenas de descobrimento de Brasis" fora escrito em 1999 e permanecera inédito até então. Entretanto, também em 2001, Bonassi publica Passaporte, um livro com 137 micronarrativas que os editores chamam de "relatos de viagem", em que não por acaso são republicados, como contos inteiros, dois daqueles parágrafos de "15 cenas de descobrimento de Brasis". Em Passaporte, para cada narrativa o autor acrescenta um ano (em que supostamente o texto foi escrito) e uma cidade com seu respectivo país, reforçando a idéia de um livro de viagens.

008 despojos de guerra

O pai de Karin foi preso bem no dia 7 de maio de 1945. Ela tinha 6 meses. Os soviéticos queriam a forra de Leningrado sem vergonha e o mandaram pra Sos'va. Ninguém soube o que ele fez, a ponto de envergar todas as unhas pra sempre. No dia em que ele voltou, dez anos depois, com os últimos prisioneiros que Adenauer foi buscar em Moscou, a mãe de Karin tinha ido drenar os pântanos de perto de Oth-Marschen. Quando Karin viu aquele homem parado na porta, foi logo oferecendo um prato de comida, pois era o certo de fazer com estranhos na época.

Hamburgo - Alemanha - 1998 (BONASSI, 2001, p. 8).

Como nos textos anteriores de Nassar e do próprio Bonassi, aqui também identificamos personagens - Karin, sua mãe, seu pai -, identificamos uma sucessividade de ações interligadas e uma significação, caracterizando uma narrativa. Indo adiante, podemos encontrar em "Despojos de guerra" uma história aparente - a menina que não reconhece seu pai - e a história oculta - qual possa ser os efeitos da guerra para toda uma geração, satisfazendo a célebre definição de conto de Piglia e a teoria do iceberg de Hemingway (cf. MOSCOVICH, 2005). Verdade que para os mais conservadores, enquadrar tais micronarrativas como conto, o mesmo gênero de $O$ Alienista, deve soar em algo como insulto. Mas, se acompanharmos a evolução da narrativa, nas últimas décadas, veremos que tal transformação obedece a uma lógica que culmina na virada de milênio.

Já no século XIX Edgar Allan Poe considerava "nefasto e mal fundado" o juízo que a extensão de uma obra deva pesar na estimação de seus méritos, algo que, segundo o célebre poeta, existiu há muito tempo na literatura (cf. EIKHENBAUM, 1971, p. 164). À época, Poe defendia a short story norte-americana em relação ao romance, tão caro aos ingleses. Era não apenas uma tentativa de traçar diferenças entre um e outro, delimitando a short story como legítimo gênero literário, como apontar vantagens desta em relação ao romance. Para Poe apenas com a brevidade e concisão do conto o leitor alcançaria a totalidade da narrativa, “à 
qual só se teria acesso mediante leitura que não ultrapassasse determinado período de tempo, fixado, segundo misteriosos cálculos, em duas horas" (cf. MOSCOVICH, 2005).

Cortázar e Hemingway, na primeira metade do século XX, debruçar-se-ão sobre as teoria de Poe e vão propor novas teses para o conto. O primeiro defende a tensão como fundamental para o texto curto - e esta seria gerada pela elipse e pelo corte - até chegarmos ao que realmente interessa no conto (grifos do autor). O segundo, tal como Poe e Cortázar, valoriza sobremaneira o adensamento narrativo e o efeito que tal intensidade (tensão) deve causar em seu leitor: "a economia de meios deve ser a todo custo preservada em nome não só da verossimilhança, mas por questões do efeito que possa vir a causar." (HEMINGWAY cf. MOSCOVICH, 2005). É do autor de $O$ Velho e o Mar, também, a já célebre teoria do iceberg, que compara o conto a um iceberg porque apenas um oitavo de seu volume está acima da água. Em outras palavras, o conto é também o não-dito, o não-escrito, e daí a relativa importância da extensão de uma obra.

Não por acaso Hemingway é também considerado a raiz da literatura minimalista americana, e o seu "Hills Like White Elephants", apontado como um dos melhores exemplos desse estilo. $\mathrm{O}$ adjetivo minimalista, aliás, desde meados dos anos 60 tem sido estirado em tantas direções que perdeu quaisquer limites a que alguma vez possa ter se proposto (BATCHELOR, 2001, p. 06). Na literatura, o minimalismo se caracteriza por um movimento idealizado pelo editor Gordon Lish e praticado, sobretudo na década de 1980, por escritores como Raymond Carver, Bobbie Ann Mason, Frederick Barthelme, entre outros (SOBREIRA, 2003). Raymond Carver, apesar de rejeitar o rótulo de minimalista por considerar a terminologia "prejorativa", é hoje o nome mais associado à literatura minimalista: seus contos de pouquíssimas linhas procuram captar a vida através de ângulos e personagens simples, tendência que marca profundamente a ficção norte-americana contemporânea e faz-se presente em autores como Sam Shepard, Richard Fox, David Leavitt e Tobias Wolfn. Este minimalismo de Carver gerou um novo gênero, nos Estados Unidos chamado de Flash fiction, ou histórias com menos de mil palavras, que mais tarde geraria outro gênero ainda - este mais reducionista do que minimalista - destinado a histórias ainda menores, com até 300 palavras, chamado de micro-fiction (THOMAS, 2005).

No Brasil, Dalton Trevisan é apontado como o grande mestre da micronarrativa desde que publicou, em 1994, o livro Ah, é?, considerado o primeiro livro de micronarrativa no País, mas batizado pela editora como sendo de "ministórias". A obra lembra Carver (e a chamada "geração maldita") não apenas pela concisão extrema como pelos temas urbanos de uma humanidade perversa e pervertida, violenta e tarada. 
Ao tirar a calcinha, ele rasga. Puxa com força e rasga. Vai por cima. Ó mãezinha, e agora? Com falta de ar, afogueada, lavada de suor. Reza que fique por isso mesmo.

Chorando, suando, tremendo, o coração tosse no joelho. Ele a beija da cabeça ao pé - mil asas de borboleta à flor da pele. O medo já não é tanto. Ainda bem só aquilo. Perdido nas voltas de sua coza, beija o umbiguinho.

Deita-se sobre ela - e entre nela. Que dá um berro de agonia: o cigarro aceso na palma da mão. Mas você pára? Nem ele (TREVISAN, 1994, p. 102).

Apesar do pioneirismo no mercado editorial, é difícil afirmar que Trevisan tenha sido o primeiro a importar para o Brasil esse tipo de ficção. Na própria antologia de Moriconi vemos outros contos com menos de 500 palavras, como "A mulher do vizinho", de Fernando Sabino, de 1962, ou “Uma vela para Dario", do próprio Dalton Trevisan, de 1964. O fato é que, a partir de $A h, e ́$ ?, operou-se uma espécie de reinvenção do gênero.

Entre agosto de 1998 e dezembro de 2001, João Gilberto Noll publica 338 pequenas narrativas na Folha de S. Paulo sob o título de "Relâmpagos" (mais tarde, em 2003, a reunião destes textos seria publicada pela Francis e o livro Mínimos, múltiplos, comuns ganharia o Prêmio Academia Brasileira de Letras em 2004). Ainda antes, em 1996, Maria Lúcia Simões publicara em Minas Gerais o livro Contos Contidos. Em 2001, Luiz Rufatto surpreende com Eles eram muitos cavalos, onde conta 70 "flashes" - definição da edição - da cidade de São Paulo, no dia 9 de maio de 2000. Os temas da violência e do desapego das relações familiares voltam a aparecer (como em Trevisan e Bonassi), somando-se a eles uma espécie de deboche do misticismo. Diferentemente dos antecessores, porém, Rufatto intercala narrativas com artigos, orações, discursos variados, gerando uma saudável confusão até no apresentador da obra: "Não sei se li um romance ou novela, se contos, registros ou espantos" (ABRAMOVICH, 2001).

Moriconi já aponta, em sua antologia, para a diversidade estética do conto nos anos 90, quando "não apenas o conto como gênero esteve muito em evidência, como também fícou patente a existência de uma tendência à diversificação estilística e temática” (MORICONI, 2001, p. 14). Foi essa espécie de ampliação do conceito de conto, aliada à força que o minimalismo alcançou em diversos campos sociais, especialmente na mídia (jornalismo e publicidade), que permitiu a gradativa aceitação por parte da crítica e do público desses microcontos reproduzidos na antologia de Cem Melhores.

Precisariam de mais alguns anos, porém, para que o reducionismo na ficção chegasse ao seu ápice; uma radicalização enriquecedora para a compreensão e estudo da nova estética. Os Cem Menores Contos Brasileiros do Século, livro organizado pelo escritor Marcelino Freire em 2004 - sob inspiração da antologia de Moriconi -, traz cem contos de até cinqüenta 
letras de renomados autores brasileiros contemporâneos como Glauco Mattoso, Sérgio Sant'Anna, Márcia Denser, Miguel Sanches Neto, Luís Augusto Fischer e, claro, Fernando Bonassi.

O resultado é uma antologia desigual, com alguns textos muito próximos ao lirismo lembrando o também o reducionista gênero haikai -, outros sem nenhuma significação aparente e ainda outros, talvez a maioria, jogando com maestria no limiar da narrativa. Vejamos um caso bem sucedido: "Uma vida inteira pela frente./O tiro veio por trás" (MOSCOVICH, 2004, p. 16).

Essas dez palavras, esses quarenta caracteres (não se conta os espaços nem a pontuação), são todo o conto. Não há título. Não há qualquer relação entre esta narrativa e a de qualquer outro autor. Ainda assim podemos identificar personagem, sucessão, conflito, história aparente e história oculta. E mesmo que o espaço não seja explícito, também não o é em diversos contos reunidos na antologia dos Cem melhores, pois o essencial numa narrativa é o que Roland Barthes chama de funções núcleo. Se a vida era de um jovem rico ou pobre, de uma menina bonita ou feia, se o dia estava quente ou frio, se o tiro foi proposital ou acidental, se as pessoas viram ou não, se alguém chorou sua morte ou não, se era homem ou mulher, não importa para o cerne desta narrativa, para este conflito urbano da violência. Isso são índices e informantes - para ficar nas categorias barthesianas - que o leitor preenche como bem entender, valendo-se de toda tradição literária e de sua própria experiência urbana.

Se cruzarmos esta micronarrativa de Moscovich com sua revisão da teoria do conto, poderíamos afirmar que um microconto como este é uma narrativa do não-dito, uma narrativa do silêncio:

Um conto é uma estrutura armada de "maneira inteligente", que tira literalmente o máximo do mínimo, que pede e convoca a participação intelectual de seu leitor, sem que se o subestime ou superestime. O ideal, conforme aponta Piglia, resumindo o que pregaram seus predecessores, é que o ponto médio entre ocultação e revelação seja mantido, introduzindo-se o leitor nesta gramática do silêncio representada pelo conto. (MOSCOVICH, 2005).

As cenas de descobrimento de Brasis de Bonassi, os relatos de viagem do seu Passaporte, as ministórias de Trevisan e as outras diversas micronarrativas aqui não reproduzidas, exploram ao máximo esse ponto médio entre ocultação e revelação, priorizando o que está oculto num jogo de esconde-esconde com o leitor. Não fosse toda uma tradição do conto, teorizada e proficuamente produzida, talvez esse leitor não alcançasse a história oculta. Mas o fato é que, fazendo a micronarrativa parte de um processo literário e social, hoje já se pode afirmar ser possível produzir uma narrativa com dez palavras. Ou até menos. 
Não que seja uma tarefa simples e segura. O mesmo Bonassi dos Cem Melhores e de Passaporte foi convidado a participar dos Cem Menores e teve publicado o seguinte texto:

SÓ

Se eu soubesse o que procuro com esse controle remoto... (BONASSI, 2004, p. 30).

A indecisão apática do eu, sua subjetividade e interiorização lembram mais um sujeito poético do que um narrador. E mesmo que ainda a partir do título "Só" se olhe o cenário de um homem solitário em frente à televisão com um controle remoto - representando a falta de sentido e objetivo para a existência humana -, falta sucessão no texto para caracterizar uma ação e dizermos que se trata de narrativa e não de poesia, pois “onde não há sucessão não há narrativa, mas, por exemplo, descrição, dedução, efusão lírica, etc. Onde não há integração, não há narrativa, mas cronologia, enunciação de uma sucessão de fatos não relacionados”. (BREMOND, 1973, p. 113-114)

Não é objetivo deste estudo fazer juízo de valor ou crítica sobre esse texto específico, e se voltamos a Bonassi é apenas porque o autor, de uma forma ou outra, esteve presente em todos os importantes momentos dessa reinvenção do microconto nos de anos 2000. O que queremos é chamar a atenção é para o fato de o mesmo Bonassi capaz de encerrar uma antologia dos melhores contos do século com um conjunto de micronarrativas, capaz de produzir um livro com mais de cem microcontos - e ainda relacioná-los a espaços históricos ou geográficos -, não consegue produzir um conto com limitações tão rígidas, pelo menos não dentro do que hoje se entende por conto, um ente do modo narrativo.

O próprio Bonassi, entretanto, que já demonstrara em Passaporte a riqueza de possibilidades dessa nova estética, também no romance, no caso Subúrbio - publicado em 1994 e reeditado com ainda mais reduções em 2005 - opera com uma linguagem contida, coesa e forte e aposta na divisão frenética de capítulos (são 74 para 290 páginas), raramente um começando do ponto em que o outro parou, características de sua obra de micronarrativas.

Estudos mais aprofundados sobre o tema, que se fazem necessários à medida que a produção das micronarrativas avançam, talvez apontem para as teorias do contemporâneo a fim de explicar ou contextualizar esse tipo de ficção. Tanto Fredric Jameson (1996) quanto David Harvey (1996) apontam a fragmentação em termos de colagem ou de jogo aleatório dos significantes. O primeiro chega a propor que o autor pós-moderno "embaralha sem cessar os fragmentos de textos preexistentes, os blocos de armar da cultura e da produção social, em uma nova bricolagem potencializada: metalivros que canibalizam outros livros, metatextos que fazem colagem de pedaços de outros textos” (JAMESON, 1996, p. 118). 
Dessa forma, os caminhos da micronarrativa ainda são desconhecidos e sua permanência questionável, mas com alguma segurança se pode afirmar que a influência na literatura de língua portuguesa dessa vertente minimalista já se faz sentir mesmo na narrativa longa. Veja o caso de José Saramago em Intermitências da Morte, quando o narrador ao explicar para "os amantes da concisão, do modo lacônico, da economia de linguagem [...] porque, sendo a idéia assim tão simples, foi preciso todo este arrazoado para chegarmos enfim ao ponto crítico", justifica-se dizendo ser "por mor do background" (SARAMAGO, 2005, p. 67). Caso muito semelhante ao de Quatro Negros, de Luís Augusto Fischer, onde narrador promete "não romancear muito, pelo menos agora, eu quero te contar lisamente, diretamente, claramente a história da Janete e sua família” (FISCHER, 2005, p. 9), justificando-se logo a seguir que é "preciso ter o ambiente adequado pra poder avaliar como é linda [a história da Janete]" (FISCHER, 2005, p. 11).

As duas narrativas foram publicadas em língua portuguesa no ano de 2005, e ambas refletem na própria escrita o que o ensaísta pernambucano Abrahão Costa Andrade chamou de angústia da concisão: “jogado e perdido no meio do anonimato das massas, o poeta já não tem mais nada a dizer, ou já não tem quem o escute" (ANDRADE, 2003, p. 92).

Fernando Bonassi, nesse contexto, seria mais o poeta adaptado ao anonimato das massas, dizendo com objetividade o que precisa ser dito, do que os narradores angustiados de Saramago ou Fischer, espremidos pela necessidade de serem breves e o desejo de serem precisos. Objetividade essa que rendeu a Bonassi a honra de encerrar uma antologia com $O s$ Cem Melhores Contos Brasileiros do Século, mas não lhe impediu de criar num espaço exíguo um texto que de longe lembra seus melhores contos, evidenciando a dificuldade inerente de contar uma história na Era do "micro".

\section{Referências}

ABRAMOVICH, Fanny. Orelha. In: RUFATTO, Luiz. Eles eram muitos cavalos. São Paulo: Boitempo Editorial, 2001.

BARTHES, Roland. Introdução à Análise Estrutural da Narrativa. In: BARTHES, Roland (org.). Análise estrutural da narrativa. São Paulo: Vozes, 1973.

BATCHELOR, David. Minimalismo. Trad. Célia Euvaldo, São Paulo: Cosac Naify, 2001.

BONASSI, Fernando. Os Cem Melhores Contos Brasileiros do Século. In: MORICONI, Ítalo (org.). Os Cem Melhores Contos Brasileiros do Século. São Paulo: Objetiva, 2001. 
BONASSI, Fernando. Passaporte. Rio de Janeiro: Cosac Naify, 2001.

BREMOND, Claude. A lógica dos possíveis narrativos. In: BARTHES, Roland (org.). Análise estrutural da narrativa. São Paulo: Vozes, 1973.

CANDIDO, Antonio et al. A personagem de ficção. São Paulo: Perspectiva, 1976.

CRIADO, Francisco J. Rodríguez. El minimalismo de Raymond Carver. In: Idea Sapiens, 2002. Disponível no endereço da WEB <http://www.ideasapiens.com/ actualidad/cultura/arte-letras/min_\%20malismo\%20_raymond\%20_carver.htm >. Acessado em 27/01/2006.

EIKHENBAUM, B. Sobre a teoria da prosa. In: EIKHENBAUM, B. Teoria da liteartura: formalistas russos. Porto Alegre: Globo, 1971.

FISCHER, Luís Augusto. Quatro Negros. Porto Alegre: L\&PM, 2005. 2 ed.

FREIRE, Marcelino. Bum!. In: Contos de Bolso. Porto Alegre: Casa Verde, 2005.

HARVEY, David. Condição pós-moderna: uma pesquisa sobre as origens da mudança cultural. São Paulo: Loyola, 1996. 6. ed.

JAMESON, Fredric. Pós-Modernismo: a lógica cultural do capitalismo tardio. São Paulo: Editora Ática, 1996.

MINIMALISM. Britannica Concise Encyclopedia, 2005. Disponível no endereço da WEB <http://www.britannica.com/ebc/article-9372219>. Acessado em 01/09/2005.

MORICONI, Ítalo. Apresentação. In: MORICONI, Ítalo (org.). Os Cem Melhores Contos Brasileiros do Século. São Paulo: Objetiva, 2001.

MOSCOVICH, Cíntia. De Poe a Piglia: em busca das teorias sobre o conto e o encontro de uma gramática do silêncio. In: Veredas, 2005. Disponível no endereço da WEB <http://www.msmidia.com/_modelo1/veredas/textos_detalhes.asp?id=182>. Acessado em 03/09/2005.

NOLL, João Gilberto. Mínimos, Múltiplos, Comuns. Rio de Janeiro: Francis, 2003.

REIS, Carlos. O conhecimento da literatura: introdução aos estudos literários. Porto Alegre: EDIPUCRS, 2003.

SARAMAGO, José. Intermitências da Morte. São Paulo: Companhia das Letras, 2005.

SOBREIRA, Ricardo da Silva. A narrativa minimalista de Sam Shepard. In: Bestiário, 2003. Disponívelzno endereço da $\quad$ WEB http://www.bestiario.com.br/8_arquivos/A\%20narrativa\%20minimalista.html>. Acessado em 27/01/2006.

THOMAS, G. W. Writing Flash Fiction. In: Fiction Factor, 2005. Disponível no endereço da WEB <http://www.fictionfactor.com/guests/flashfiction.html>. Acessado em 27/01/2006. 
TREVISAN, Dalton. Ah, é?. Rio de Janeiro: Record, 1994. 